\title{
Enhanced peripheral toll-like receptor responses in psychosis: further evidence of a pro-inflammatory phenotype
}

\author{
DP McKernan ${ }^{1}$, U Dennison ${ }^{2}$, G Gaszner ${ }^{2}$, JF Cryan $^{1,3,4}$ and TG Dinan ${ }^{1,2}$
}

Low-grade peripheral inflammation is often present in psychotic patients. Toll-like receptors (TLRs) are pattern-recognition molecules that initiate inflammation. Our objective was to investigate the peripheral TLR activity in psychosis. Forty schizophrenia patients, twenty bipolar patients and forty healthy controls $(\mathrm{HC})$ were recruited. Donated whole blood was cultured with TLR agonists for $24 \mathrm{~h}$. Cell supernatants were analysed using a multiplex enzyme-linked immunosorbent assay approach to measure IL-1 1, IL-6, IL-8 and tumour necrosis factor- $\alpha$ (TNF $\alpha$ ). Plasma was analysed for cytokines, cortisol and acute phase proteins. Here, we show that selective TLR agonist-induced cytokine (IL-1ß, IL-6, IL-8 and TNF $\alpha$ ) release is enhanced in stimulated whole blood from schizophrenia and bipolar patients compared with HC. An exaggerated release of IL-1 $\beta$, IL-6 and TNF $\alpha$ following treatment with the TLR2 agonist HKLM was detected in both disorders compared with controls. Enhanced TLR4induced increases in IL-1 $\beta$ for both disorders coupled with TNF $\alpha$ increases for bipolar patients were observed. TLR8-induced increases in IL-1 $\beta$ for both disorders as well as IL- 6 and TNF $\alpha$ increases for bipolar patients were detected. TLR9-induced increases in IL-8 for schizophrenia patients were also observed. No differences in TLR1, TLR3, TLR5, TLR6 or TLR7 activity were detected. Plasma levels of IL- 6 were significantly elevated in bipolar patients while TNF $\alpha$ levels were significantly elevated in schizophrenia patients compared with controls. Plasma acute phase proteins were significantly elevated in bipolar patients. These data demonstrate that specific alterations in TLR agonist-mediated cytokine release contribute to the evidence of immune dysfunction in psychotic disorders.

Translational Psychiatry (2011) 1, e36; doi:10.1038/tp.2011.37; published online 30 August 2011

\section{Introduction}

Schizophrenia is a psychiatric disorder that affects $\sim 1 \%$ of population. The main clinical features are positive symptoms (delusions, hallucinations and thought disorder), negative symptoms (social withdrawal and flattening of emotional responses) and cognitive impairment (attention and memory deficits). ${ }^{1,2}$ There is a strong genetic association ${ }^{3}$ and a common association with prenatal infection. ${ }^{4}$ Prenatal infection (bacterial and viral) and the resulting inflammation may affect development of cortical neurons as demonstrated in rat models. ${ }^{5-7}$ Increasing evidence suggests distinct immunological alterations in schizophrenia. These include elevations in acute phase proteins (haptoglobin, fibrinogen, complement, acid glycoprotein and hemopexin), ${ }^{8}$ and alterations in plasma pro-inflammatory cytokines such as IL-1RA, sIL2R and IL-6 have also been reported. ${ }^{9}$

Bipolar disorder represents a category of mood disorders defined by episodes of hypomania/mania (feelings of elation with elevated energy/activity levels and reduced sleep) and episodes of depression (low mood, anhedonia, low energy levels, loss of motivation, change of sleep and appetite).$^{10}$ It affects $\sim 2 \%$ of the general population. ${ }^{11}$ For many sufferers, genetic factors have an important role in the aetiology. ${ }^{10}$ In addition, several studies report elevated levels of pro-inflammatory cytokines in bipolar patients compared with healthy controls $(\mathrm{HC})$. Specifically, elevated plasma levels of tumour necrosis factor- $\alpha(\mathrm{TNF} \alpha),{ }^{12-14}$ interleukin-2 (IL-2) and interleukin-4 (IL-4) $)^{14,15}$ have been reported in manic bipolar patients whereas increases in IL- $8^{13}$ and IL- $6{ }^{14}$ were reported in depressed bipolar patients. In line with this inflammatory phenotype, serum chemokine levels were found to be altered in euthymic bipolar patients, with elevated levels of $\mathrm{C}-\mathrm{X}-\mathrm{C}$ motif chemokine 10 and lower levels of chemokine (C-C motif) ligand $24 .{ }^{16}$

Toll-like receptors (TLRs) are a pivotal component of the innate immune system. These receptors comprise of ten members (TLR1-10) in humans and are activated by various components of both bacteria and viruses for example, TLR4 binds lipopolysaccharide in gram-negative bacteria and TLR7 binds single-stranded RNA (ssRNA) from viruses as well as some endogenous proteins. ${ }^{17}$ In a cellular context, they are located both at the cell membrane (TLR1, 2, 4, 5 and 6) and also on intracellular endosomes (TLR 3, 7, 8 and 9). The extracellular receptors tend to engage with bacterial

\footnotetext{
${ }^{1}$ Alimentary Pharmabiotic Centre, University College Cork, Cork, Ireland; ${ }^{2}$ Department of Psychiatry, University College Cork, Cork, Ireland; ${ }^{3}$ School of Pharmacy, University College Cork, Cork, Ireland and ${ }^{4}$ Department of Pharmacology \& Therapeutics, University College Cork, Cork, Ireland Correspondence: Dr DP McKernan, Alimentary Pharmabiotic Centre, University College Cork, Western Road, Cork, Ireland. E-mail: d.mckernan@ucc.ie

Keywords: bipolar disorder; inflammation; schizophrenia; toll-like receptor

Received 27 April 2011; revised 21 June 2011; accepted 30 July 2011
} 
components external to the cell. The intracellular TLRs tend to engage with nucleic acids from bacteria and viruses that have penetrated the cell. ${ }^{17}$ These receptors tend to form homo- or heterodimers with other TLR members. Following receptor binding, a cellular protein cascade is initiated, which results in the activation of NF- $\mathrm{KB}$ among other transcription factors, which in turn transcribes inflammatory cytokines. ${ }^{17}$ TLRs are present on various cell types and are found in high numbers on mucosal surfaces (for example, the colonic and bronchial epithelium) and also on monocytic cells in peripheral blood. ${ }^{18}$ Altered levels of plasma inflammatory cytokines in schizophrenia and bipolar patients led us to investigate if altered TLR activity may be a possible cause. Our aim was to characterise the activity of various TLRs in peripheral blood in psychotic patients.

\section{Materials and methods}

Subject population. The study protocol (APC021 2009), including all procedures, was approved by the Cork University Hospital ethics committee. Forty $\mathrm{HC}$ were recruited from laboratory or hospital staff. Forty schizophrenia patients and twenty bipolar patients aged between 18-65 years of age, who satisfied DSM-IV (diagnostic and statistical manual of mental disorders) criteria for the diagnosis of schizophrenia and bipolar disorder (based on a structured clinical interview), were recruited from psychiatric clinics and inpatient wards at Cork University Hospital. Individuals with inflammatory diseases, coeliac disease, lactose intolerance, immunodeficiency and individuals who had undergone any abdominal surgery, with the exception of hernia repair and appendectomy were excluded. Each potentially eligible patient donated $20 \mathrm{ml}$ venous blood (between 09:00-12:00 h), and was evaluated by psychiatrist using a full review of clinical history, including current health status, body mass index, family history, current medication and psychiatric evaluation.

Questionnaires and psychiatric rating scales. In the schizophrenia cohort, symptoms were objectively rated by a psychiatrist according to the administered positive and negative symptom scale (PANSS). This is a 30 -item scale that measures positive symptoms, negative symptoms, their differential and general psychopathology symptoms. Total overall scores range from 30 to 210 , with a cutoff of $\leqslant 60$ for mild illness severity, 61 to $\leqslant 75$ for moderate severity and $>75$ for markedly severe illness. ${ }^{19,20}$ The Calgary depression scale for schizophrenia was also completed for all patients to assess comorbid depressive symptomatology. It is an observer-rated scale, with a cutoff of $\geqslant 6$ indicating concurrent depression. ${ }^{21}$ In the bipolar cohort, symptoms were objectively measured using the Young mania rating scale and the Hamilton depression rating scale. The Young mania rating scale is a clinician-administered scale that rates the severity of mania. There are 11 items in total, measuring symptoms such as elevated mood, irritability, sleep, behaviour and insight. The total achievable score is 60, with a score of $\leqslant 7$ indicating remission. The Hamilton depression rating scale is also a clinician-rated scale for assessing the severity of depression. It consists of 17 items (including disturbances in mood, sleep, appetite and weight, anxiety, agitation, somatic symptoms and suicidal ideation). There is a maximum possible score of 45 . A score of $\leqslant 7$ indicates remission; 8-13 mild depression; 14-18 moderate depression; 19-23 severe depression and $>24$ very severe depression. ${ }^{22-24}$

Plasma isolation and whole-blood culture. Whole blood ( $15 \mathrm{ml}$ of the $20 \mathrm{ml}$ collected) was added to an equal volume of Histopaque 1077 (Sigma, St Louis, MO, USA) in a sterile $50-\mathrm{ml}$ tube and centrifuged at $400 \mathrm{~g}$ for $30 \mathrm{~min}$ at room temperature. Plasma on the upper layer was transferred to a separate tube and stored at $-80^{\circ} \mathrm{C}$ for future use. Whole blood ( $2 \mathrm{ml}$ of the $20 \mathrm{ml}$ collected) was diluted 1:10 in Dulbecco's Modified Eagle's Medium (Gibco, Dublin, Ireland). Blood was aliquoted into 24-well plates, and cultured in $37^{\circ} \mathrm{C}$ incubator with $5 \% \quad \mathrm{CO}_{2}$. Each blood sample was cultured in Dulbecco's Modified Eagle's Medium cell culture medium supplemented with $10 \%$ Foetal Calf Serum with or without the following TLR ligands from Human TLR agonist kit (InvivoGen, San Diego, CA, USA) for $24 \mathrm{~h}$ : TLR1/2-palmitoyl-3-cysteine-serine-lysine 4; TLR2-heat-killed Listeria Monocytogenes; TLR3polyriboinosinic polyribocytidylic acid; TLR4-lipopolysaccharide; TLR5—Salmonella typhimurium Flagellin; TLR6/ 2- Pam $_{2}$ CGDPKHPKSF (FSL-1); TLR7-Imiquimod; TLR8-ssRNA40; TLR9-ODN2006. Agonists were reconstituted in endotoxin-free water (supplied) with a final concentration of $1 \mu^{g_{~ m l}}{ }^{-1}$ except for HKLM ( $10^{8}$ cells), Poly $\mathrm{I}: C 10 \mu \mathrm{g} \mathrm{ml}^{-1}$ and ODN2006 $5 \mu \mathrm{M}$. Each treatment was carried out in duplicate. After the indicated culture period, supernatant from both untreated and stimulated cells was aspirated and stored at $-80^{\circ} \mathrm{C}$ for cytokine analysis at a later date.

Enzyme-linked immunosorbent assay. Measurements of pro-inflammatory cytokines IL-1 $\beta$, IL-6, IL-8 and TNF $\alpha$ in both plasma and following TLR agonist stimulation of whole blood was carried out using the Meso Scale Discovery 4-plex human pro-inflammatory kit II (Meso Scale Discovery, Gaithersburg, MD, USA). Plasma C-reactive protein and serum amyloid A were also measured using Meso Scale Discovery kits. Enzyme-linked immunosorbent assay plates were analysed using the Sector 2400 imager from Meso Scale Discovery. This is an ultra-sensitive method, which has a detection limit for $\mathrm{IL}-1 \beta$ of $0.3 \mathrm{pg} \mathrm{m}^{-1}, \mathrm{IL}-6$ of $0.3 \mathrm{pg} \mathrm{ml}^{-1}$, IL-8 of $1.0 \mathrm{pg} \mathrm{m}^{-1}$ and TNF $\alpha$ of $0.3 \mathrm{pg} \mathrm{ml}^{-1}$. Plasma cortisol was measured using the cortisol enzyme immunoassay kit (Assay Designs, Ann Arbor, MI, USA) with a detection limit of $26.99 \mathrm{pg} \mathrm{ml}^{-1}$.

Statistical analysis. The sample size was determined by a power calculation based on our previous data and aimed at detecting differences between schizophrenia patients, bipolar patients and $\mathrm{HC}$ at the 0.05 level. Enzyme-linked immunosorbent assay data were expressed as mean \pm s.e.m. and plotted as a histogram showing $\mathrm{HC}$, schizophrenia and bipolar patients for each TLR and cytokine analysed. All statistical analysis was carried out using 
Table 1 Demographic data were collected from medical history

\begin{tabular}{|c|c|c|c|}
\hline & Healthy controls $(\mathbb{N}=40)$ & Schizophrenia $(\mathbb{N}=40)$ & Bipolar disorder $(\mathrm{N}=20)$ \\
\hline Age (years) & $36.20 \pm 1.758$ & $38.33 \pm 1.699$ & $38.50 \pm 2.630$ \\
\hline Sex & $13 \bar{M}, 27 \mathrm{~F}$ & $24 \mathrm{M}, 16 \mathrm{~F}$ & $10 \mathrm{M}, 10 \mathrm{~F}$ \\
\hline Height (m) & $1.706 \pm 0.01618$ & $1.733 \pm 0.01141$ & $1.691 \pm 0.02084$ \\
\hline Weight (kg) & $69.74 \pm 2.591$ & $84.01 \pm 2.883^{\star \star \star}$ & $75.12 \pm 2.664$ \\
\hline $\mathrm{BMI}\left(\mathrm{kg} \mathrm{m}^{-2}\right)$ & $23.89 \pm 0.8261$ & $27.94 \pm 0.8507^{\star *}$ & $26.30 \pm 0.9255$ \\
\hline PANSS total score & $\mathrm{N} / \mathrm{A}$ & $60.36 \pm 2.45$ & $\mathrm{~N} / \mathrm{A}$ \\
\hline YMRS & $\mathrm{N} / \mathrm{A}$ & $N / A$ & $16 \pm 2.517$ \\
\hline HDRS & N/A & $\mathrm{N} / \mathrm{A}$ & $9 \pm 2.646$ \\
\hline History of depression & 0 & 19 & 20 \\
\hline Family history psychosis & 0 & 11 & 3 \\
\hline Family history depression & 3 & 9 & 6 \\
\hline Family history bipolar & 0 & 2 & 9 \\
\hline
\end{tabular}

Abbreviations: BMI, body mass index; HDRS, Hamilton depression rating scale; N/A, not applicable; PANSS, positive and negative symptom scale; YMRS, Young mania rating scale.

Data from psychiatric rating scales are also shown. Data are expressed as mean \pm s.e.m. Analysis of variance was used to determine significant differences. ${ }^{\star \star} P<0.01$ vs Ctrl. ${ }^{\star \star \star} P<0.001$ vs Ctrl.

GraphPad Prism for Windows (Version 5, La Jolla, CA, USA). Before analysis, the data were examined for normality using the Kolmogorov-Smirnov test. Plasma cytokine levels were compared using one-way analysis of variance (ANOVA) with a Bonferroni post-hoc test, differences were considered significant at $P<0.05$. Differences between the schizophrenia, bipolar and control groups for TLR-agonistinduced release of cytokines were determined using two-way ANOVA with a Bonferroni post-hoc test.

\section{Results}

Demographic data. Demographic data are shown in Table 1 while information on medications is shown in Table 2. No significant difference was found between the groups for age (Table 1). A significant difference was found between the groups for weight $(P=0.0008)$ and, as a result, for body mass index $(P=0.0026)$ using ANOVA. The schizophrenia cohort significantly weighed more than $\mathrm{HC}$ $(P<0.001)$ (Table 1). In our cohort of 40 patients with schizophrenia, 20 patients had mild illness severity, 13 had moderate and 7 had severe illness severity according to the above cutoffs using the PANSS rating scale. The average total score for PANSS was $60.36 \pm 2.45$, indicating the average severity was mild.

Of the schizophrenia cohort, 19 patients had a previous clinical diagnosis of depression according to DSM-IV criteria compared with 20 of the bipolar cohort and none of the HC. Using the Calgary depression scale for schizophrenia, a total of nine of our schizophrenia cohort satisfied a diagnosis of depression according to these criteria. $^{21}$ Using the Young mania rating scale and Hamilton depression rating scale to assess bipolar symptoms, a total of seven patients were in disease remission according to cutoffs of $\leqslant 7$ on both these scales. Seven patients scored $\geqslant 8$ on the Young mania rating scale indicating manic relapse. Six patients scored $>7$ on the Hamilton depression rating scale indicating depressive relapse. Within the control group, three had a family history of depression, compared with nine of the schizophrenia group and six of the bipolar group. In the schizophrenia group, 11 patients had a family history of mood disorder ( 2 bipolar disorder and 9 unipolar depression) while 15 of the bipolar
Table 2 Shown is a list of psychiatric medications taken by schizophrenia and bipolar patients

Schizophrenia Bipolar disorder

$\begin{array}{lrr}\text { One antipsychotic } & 26 & 13 \\ \text { Two antipsychotics } & 13 & 4 \\ \text { Three antipsychotics } & 1 & 0 \\ \text { No antipsychotic } & 1 & 3 \\ \text { Clozapine } & 18 & 1 \\ \text { Olanzapine } & 9 & 5 \\ \text { Risperidone } & 8 & 3 \\ \text { Amisulpride } & 4 & 0 \\ \text { Haloperidol } & 4 & 3 \\ \text { Fluphenazine } & 3 & 0 \\ \text { Quetiapine } & 2 & 7 \\ \text { Aripiprazole } & 2 & 1 \\ \text { Trifluoperazine } & 1 & 0 \\ \text { Sertindole } & 1 & 0 \\ \text { Sulpride } & 1 & 0 \\ \text { SSRls } & 9 & 0 \\ \text { NARls } & 1 & 0 \\ \text { SNRI } & 1 & 2 \\ \text { TCAs } & 1 & 2 \\ \text { Lithium } & 0 & 11 \\ \text { Valproate } & 2 & 8 \\ \text { Lamotrignine } & 0 & 4 \\ \text { Carbamazepine } & 2 & 0 \\ \text { Benzodiazepine } & 10 & 14 \\ \text { Non-benzodiazepine hypnotics } & 3 & 4\end{array}$

NARIs, noradrenaline reuptake inhibitors; SNRI, selective noradrenaline reuptake inhibitors; SSRIs, selective serotonin reuptake inhibitors; TCAs, tricyclic antidepressants.

This includes the total numbers on antipsychotics and numbers on individual antipsychotics as well as antidepressants, mood stabilizers and hypnotics.

patients had a family history of mood disorder ( 9 bipolar disorder and 6 unipolar depression). None of the control group had a family history of psychosis compared with 11 of the schizophrenia group and 3 of the bipolar group (Table 1).

Plasma cytokine, acute phase proteins and cortisol levels. Plasma from $\mathrm{HC}$, schizophrenia and bipolar patients was analyzed for cytokines, acute phase proteins and cortisol. ANOVA confirmed that there were no significant differences in the levels of cortisol between groups (Figure 1a). ANOVA showed a significant difference in plasma IL-6 levels $(P=0.031)$, IL-8 levels $(P=0.0014)$ and TNF $\alpha$ levels $(P=0.0007)$. Post-hoc tests showed that bipolar 

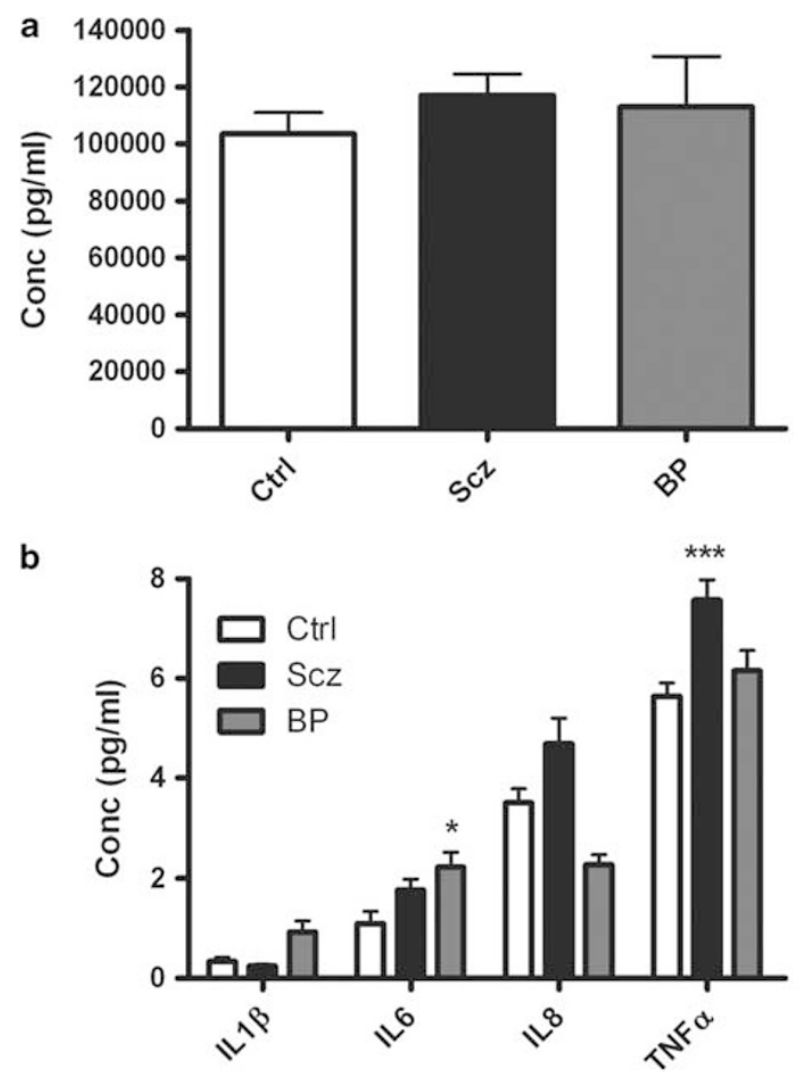

C

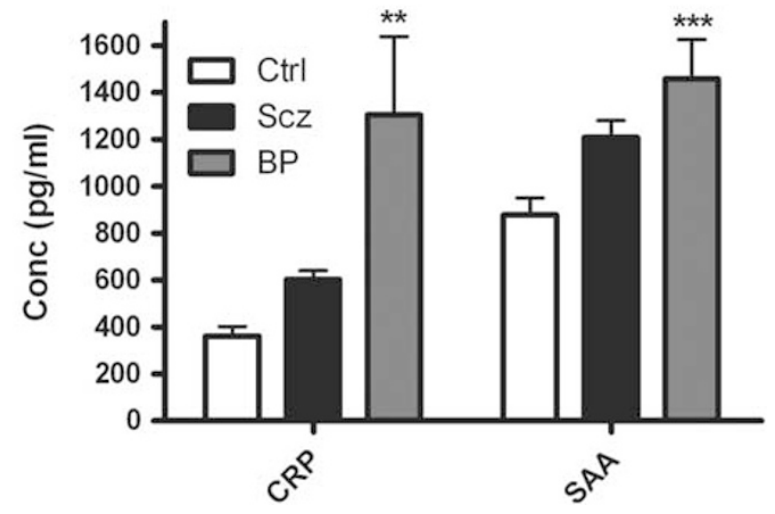

Figure 1 Shown is a graph of plasma (a) cortisol, (b) cytokine and (c) acute phase protein levels in healthy controls (Ctrl), schizophrenia (Scz) and bipolar (BP) patients measured using enzyme-linked immunosorbent assay. Data shown are expressed as mean \pm s.e.m. Statistical differences between groups were determined using ANOVA. ${ }^{*} P<0.05$, ${ }^{\star \star} P<0.01,{ }^{* \star *} P<0.001$ vs Ctrl. CRP, plasma C-reactive protein; SAA, serum amyloid $A$.

patients had elevated levels of plasma IL-6 $(P<0.05)$ compared with $\mathrm{HC}$ while schizophrenia patients had elevated levels of plasma TNF $\alpha(P<0.001)$ compared with HC (Figure 1b). ANOVA showed significant differences in plasma C-reactive protein levels $(P=0.0028)$ and serum amyloid A levels $(P=0.002)$ between groups. Post-hoc tests revealed that bipolar patients had elevated plasma levels of both $\mathrm{C}$-reactive protein $(P<0.01)$ and serum amyloid $\mathrm{A}$ $(P<0.001)$ compared with $\mathrm{HC}$. These differences remain significant when body mass index is added as a covariate.

TLR agonist cytokine release. Supernatants from wholeblood treatments with TLR agonists of $\mathrm{HC}$, schizophrenia and bipolar patients were analysed for levels of four different pro-inflammatory cytokines IL-1 $\beta$, IL-6, IL-8 and TNF $\alpha$. Twoway ANOVA demonstrated a significant effect of both disease state $\left(F_{2}, \quad 1903=25.92, \quad P<0.0001\right)$ and TLR agonist treatment $\left(F_{9}, \quad 1903=169.5, \quad P<0.0001\right)$ with a significant interaction $\left(F_{18,1903}=7.05, P<0.0001\right)$ between the two factors for IL-1 $\beta$ levels. A significant effect of both disease state $\left(F_{2,1892}=5.81, P=0.0031\right)$ and treatment $\left(F_{9}\right.$, $1892=198.9, P<0.001)$ with a significant interaction $\left(F_{18}\right.$, $1892=4.63, P<0.0001$ ) between the two factors was found for IL-6 levels. Two-way ANOVA demonstrated a significant effect of both disease state $\left(F_{2,1924}=35.69, P<0.0001\right)$ and treatment $\left(F_{9,1924}=57.23, P<0.0001\right)$ but not a significant interaction $\left(F_{18}, 1924=1.132, P>0.05\right)$ between the two factors for IL-8 levels. A significant effect of both disease state $\left(F_{2}, \quad 1927=32.44, \quad P<0.0001\right)$ and treatment $\left(F_{9}\right.$, $1927=135.8, P<0.0001)$ with a significant interaction $\left(F_{18}\right.$, $1927=8.542, P<0.0001)$ between the two factors for TNF $\alpha$ levels was also found.

Post-hoc analysis of individual treatments test revealed significant differences between schizophrenia patients, bipolar patients and HC. In the untreated blood, levels of IL-8 were found to be significantly higher in both schizophrenia (4562 $\pm 255 \mathrm{pg} \mathrm{ml}^{-1} ; P<0.001$ ) and bipolar disorder patients (4283 $\left.\pm 117 \mathrm{pg} \mathrm{ml}^{-1} ; \quad P<0.05\right) \quad$ compared withHC $\left(3077 \pm 298 \mathrm{pg} \mathrm{ml}^{-1}\right)$ (Figure 2a). No significant differences were found in cytokine release following treatment with the TLR1/2 agonist Pam3Csk (Figure $2 b$ ). IL-1 $\beta$ release was found to be significantly elevated in schizophrenia $\left(1949 \pm 167 \mathrm{pg} \mathrm{ml}^{-1} ; P<0.001\right)$ and bipolar disorder patients $\left(2597 \pm 267 \mathrm{pg} \mathrm{ml}^{-1} ; \quad P<0.001\right)$ compared with $\mathrm{HC}$ blood $\left(957 \pm 114 \mathrm{pg} \mathrm{m}^{-1}\right)$ following treatment with the TLR2 agonist HKLM. In addition, IL-1 $\beta$ release was significantly greater in bipolar disorder compared with schizophrenia patients $(P<0.001)$.

IL-6 release was significantly elevated in schizophrenia (2675 $\left.\pm 259 \mathrm{pg} \mathrm{ml}^{-1} ; P<0.05\right)$ and bipolar disorder patients $\left(3810 \pm 262 \mathrm{pg} \mathrm{ml}^{-1} ; \quad P<0.001\right)$ compared with $\mathrm{HC}$ blood $\left(2040 \pm 208 \mathrm{pg} \mathrm{ml}^{-1}\right)$. In addition, IL-6 release was significantly greater in bipolar disorder compared with schizophrenia patients $(P<0.001)$. TNF $\alpha$ release was found to be significantly elevated in schizophrenia $\left(2197 \pm 247 \mathrm{pg} \mathrm{ml}^{-1}\right.$; $P<0.001)$ and bipolar disorder patients $\left(3753 \pm 461 \mathrm{pg} \mathrm{ml}^{-1}\right.$; $P<0.001)$ compared with $\mathrm{HC}$ blood $\left(1134 \pm 164 \mathrm{pg} \mathrm{ml}^{-1}\right)$. In addition, TNF $\alpha$ release was greater in bipolar disorder patients compared schizophrenia patients $(P<0.001)$ (Figure 2c).

No significant differences were found in cytokine release following treatment with the TLR3 agonist Poly I:C (Figure $2 d$ ). IL-1 $\beta$ was found to be significantly elevated in schizophrenia $\left(2409 \pm 181 \mathrm{pg} \mathrm{ml}^{-1} ; P<0.05\right)$ and bipolar disorder patients $\left(2859 \pm 260 \mathrm{pg} \mathrm{ml}^{-1} ; P<0.001\right)$ compared with $\mathrm{HC}\left(1961 \pm 131 \mathrm{pg} \mathrm{ml}^{-1}\right)$ following treatment with the TLR4 agonist lipopolysaccharide. IL-8 release was significantly lower in bipolar disorder patients $\left(4875 \pm 77 \mathrm{pg} \mathrm{ml}^{-1}\right.$ ) compared with schizophrenia blood $\left(6146 \pm 231 \mathrm{pg} \mathrm{m}^{-1}\right)$. $\mathrm{TNF} \alpha$ release was found to be significantly elevated in bipolar disorder patients $\left(3332 \pm 376 \mathrm{pg} \mathrm{ml}^{-1} ; \quad P<0.001\right)$ 

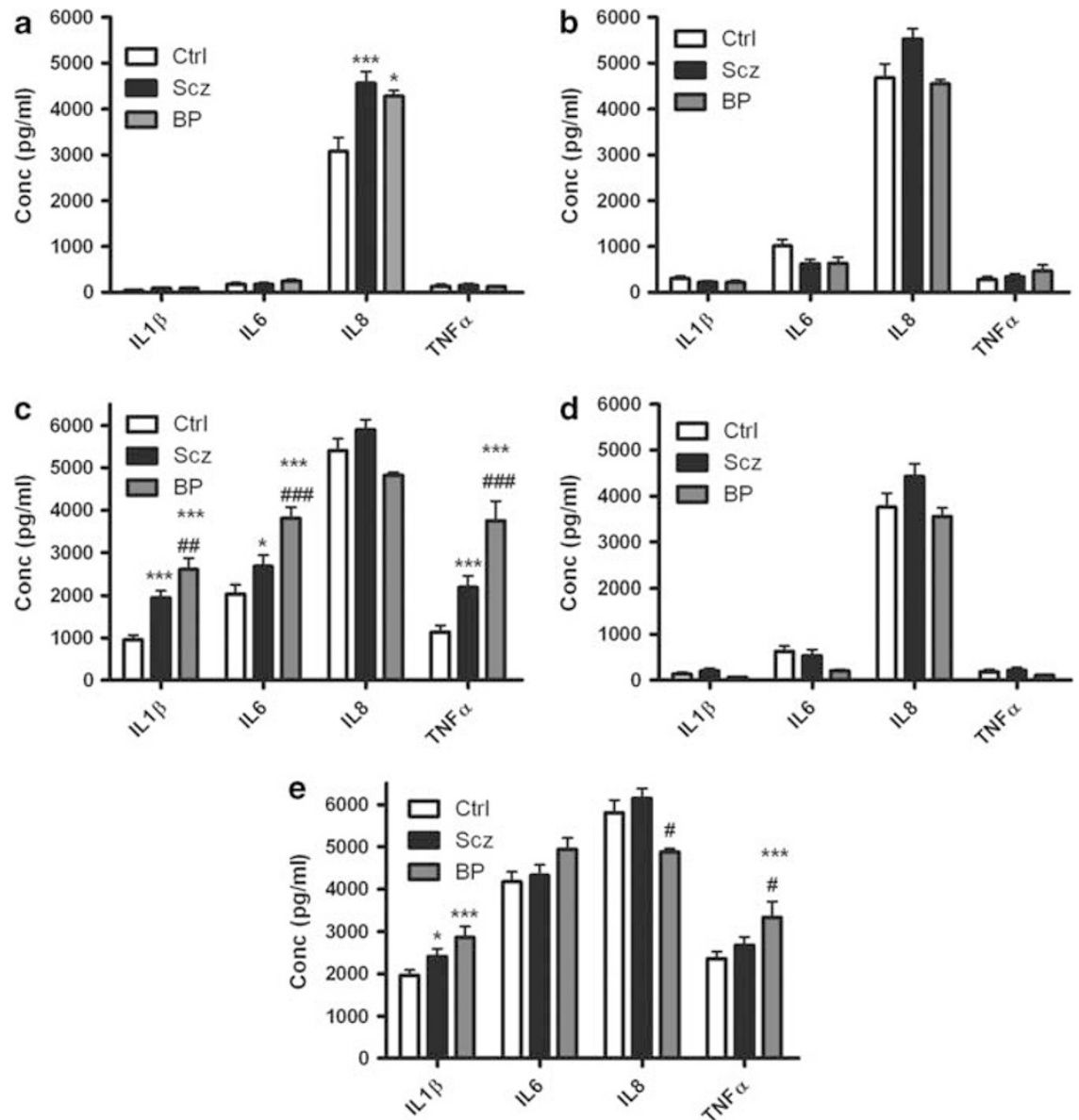

Figure 2 Shown is a graph of IL-1 $\beta$, IL-6, IL-8 and TNF $\alpha$ levels in stimulated whole-blood supernatants taken from HC (Ctrl), schizophrenia (Scz) and bipolar (BP) patients measured using enzyme-linked immunosorbent assay following (a) no treatment or treatment with the (b) TLR1/2 agonist Pam3Csk, (c) TLR2 agonist HKLM, (d) TLR3 agonist Poly I:C or (e) TLR agonist lipopolysaccharide for $24 \mathrm{~h}$. Data shown are expressed as mean \pm s.e.m. Statistical differences between treatments and disease states were determined using two-way ANOVA with Bonferroni post-hoc test. ${ }^{\star} P<0.05$, ${ }^{\star \star \star} P<0.001$ vs Ctrl; ${ }^{\#} P<0.05$, ${ }^{\# \#} P<0.01$, ${ }^{\# \# \#} P<0.001$ bipolar disorder vs schizophrenia.

compared with $\mathrm{HC}$ blood $\left(2361 \pm 164 \mathrm{pg} \mathrm{ml}^{-1}\right)$. In addition, $\mathrm{TNF} \alpha$ release was significantly greater in bipolar disorder patients compared with schizophrenia blood $(P<0.05)$ (Figure 2e).

No significant differences in cytokine release compared with controls were found following treatment with the TLR5 agonist flagellin. However, IL-8 release was significantly lower in bipolar disorder patients $\left(4690 \pm 89 \mathrm{pg} \mathrm{ml}^{-1} ; P<0.05\right)$ compared with schizophrenia $\left(5934 \pm 247 \mathrm{pg} \mathrm{ml}^{-1}\right)$. In addition, $\mathrm{TNF} \alpha$ release was greater in bipolar disorder patients $\left(1860 \pm 375 \mathrm{pg} \mathrm{ml}^{-1} ; P<0.05\right)$ compared with schizophrenia $\left(1196 \pm 121 \mathrm{pg} \mathrm{ml}^{-1}\right)$ (Figure 3a). No significant differences in cytokine release were found following treatment with the TLR6/2 agonist FSL1 (Figure 3b) or the TLR7 agonist Imiquimod (Figure $3 \mathrm{c}$ ). IL-1 $\beta$ release was found to be significantly elevated in schizophrenia $\left(1835 \pm 203 \mathrm{pg} \mathrm{ml}^{-1}\right.$; $P<0.001)$ and bipolar disorder patients $\left(2282 \pm 232 \mathrm{pg} \mathrm{ml}^{-1}\right.$; $P<0.001)$ compared with $\mathrm{HC}\left(1181 \pm 120 \mathrm{pg} \mathrm{ml}^{-1}\right)$ following treatment with the TLR8 agonist ssRNA40.

IL-6 release was found to be significantly elevated in bipolar disorder $\left(2484 \pm 253 \mathrm{pg} \mathrm{ml}^{-1} ; P<0.05\right)$ compared with controls $\left(1631 \pm 152 \mathrm{pg} \mathrm{ml}^{-1}\right)$. In addition, IL-6 release was greater in bipolar disorder compared with schizophrenia patients $(P<0.01)$. TNF $\alpha$ release was found to be significantly elevated in bipolar disorder patients $\left(2472 \pm 323 \mathrm{pg} \mathrm{ml}^{-1}\right.$; $P<0.001)$ compared with controls $\left(1132 \pm 117 \mathrm{pg} \mathrm{ml}^{-1}\right)$ following treatment with the ssRNA40. In addition, TNF $\alpha$ release was greater in bipolar disorder compared with schizophrenia patients $(P<0.01)$ (Figure $3 d)$. IL-8 release was found to be significantly elevated in schizophrenia patients $\left(2255 \pm 339 \mathrm{pg} \mathrm{ml}^{-1} ; P<0.05\right)$ compared with controls $\left(1104 \pm 276 \mathrm{pg} \mathrm{ml}^{-1}\right)$ following treatment with the TLR9 agonist ODN2006. In addition, IL-8 release was lower in bipolar disorder compare with schizophrenia patients $(P<0.05)$ (Figure 3e). Entering body mass index as a covariate did not alter the significance of the findings.

\section{Discussion}

The exact pathophysiology of schizophrenia and bipolar disorder is still unknown. Immune activation has been reported in a number of studies for both disorders, showing increases in particular pro-inflammatory cytokines. ${ }^{9,12,13}$ Whether this is central to disease progression or is an epiphenomenon is unclear. The cause of the elevations in certain cytokines seen in schizophrenia and bipolar patients has yet to be determined. We hypothesized that TLR activity may be altered in psychiatric patients. 

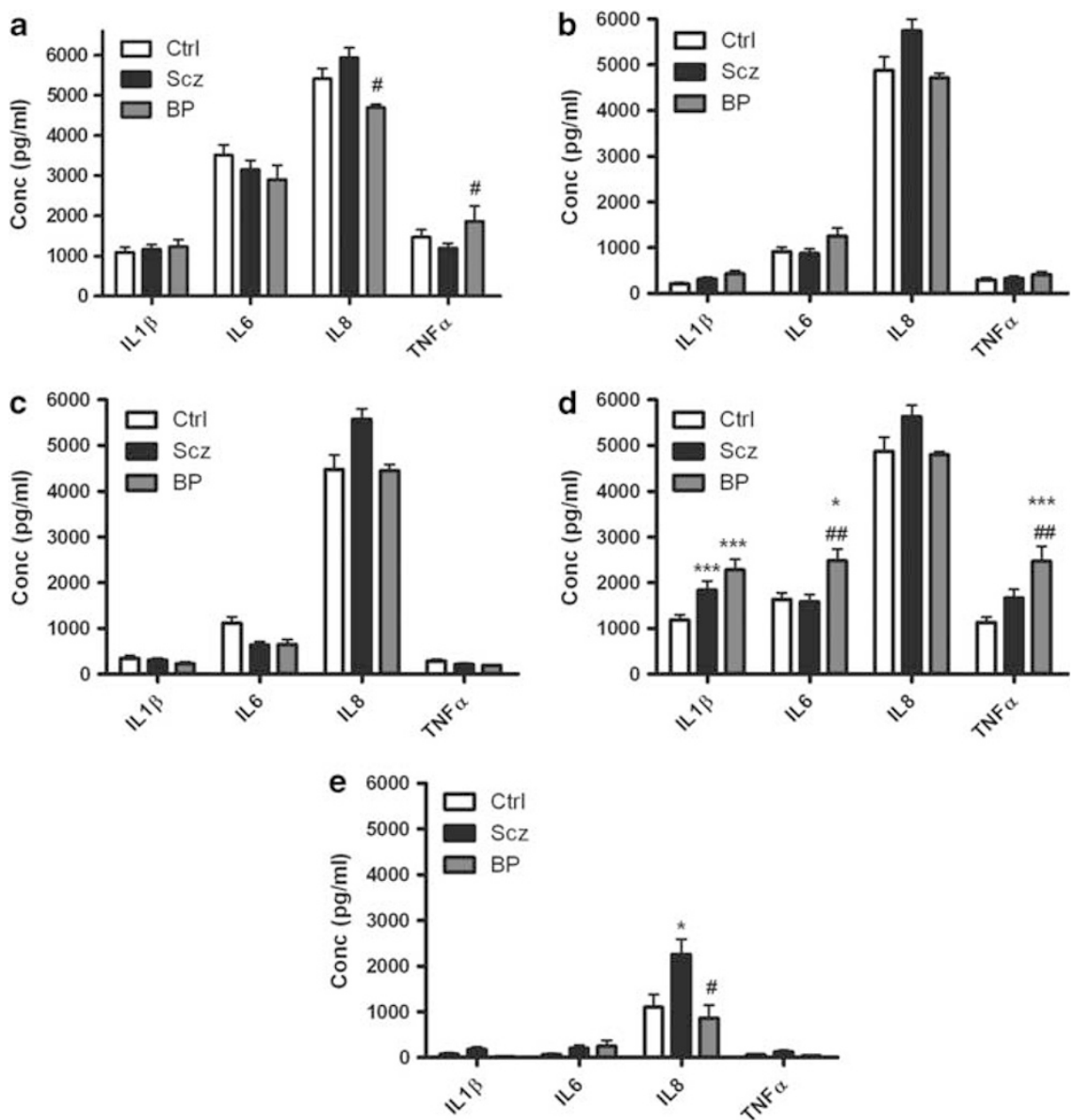

Figure 3 Shown is a graph of IL-1 $\beta$, IL-6, IL-8 and TNF $\alpha$ levels in stimulated whole-blood supernatants taken from HC (Ctrl), schizophrenia (Scz) and bipolar (BP) patients measured using enzyme-linked immunosorbent assay following treatment with (a) TLR5 agonist Flagellin, (b) TLR6/2 agonist FSL1, (c) TLR7 agonist Imiquimod, (d) TLR8 agonist ssRNA40 or (e) TLR9 agonist ODN2006 for $24 \mathrm{~h}$. Data shown are expressed as mean \pm s.e.m. Statistical differences between treatments and untreated were determined using two-way ANOVA with Bonferroni post-hoc test. ${ }^{\star} P<0.05$, ${ }^{\star \star \star} P<0.001$ vs $\mathrm{Ctrl}$; ${ }^{\#} P<0.05,{ }^{\# \#} P<0.01$, bipolar disorder vs schizophrenia.

In this study, both schizophrenia and bipolar patients were shown to have elevated plasma cytokines and acute phase proteins. The effects of elevated cytokine levels on the pathophysiology of these disorders remain to be precisely defined. Cytokines are known to have an effect on the HPA axis and stress response. ${ }^{25} \mathrm{IL}-1 \beta$, IL- 6 and TNF $\alpha$ have all been reported to stimulate secretion of corticotrophin-releasing hormone in rat as well as in humans. ${ }^{26,27}$ Cytokines are thought to be able to cross the blood-brain barrier or, at least, stimulate cells at the barrier to release more cytokines within the brain. ${ }^{27}$ During development and especially following maternal infection and inflammation, cytokines have been reported to affect cortical neuronal development, ${ }^{6,28}$ and, by so doing, may have a sustainable effect.

Whole-blood stimulations revealed a distinct pattern of peripheral TLR activity in both schizophrenia and bipolar patients. It was apparent that the exaggerated effects of HKLM, the TLR2 agonist, were the most striking result in both disorders, with TLR4 and TLR8 activities also enhanced. No differences in TLR1, TLR3, TLR5, TLR6 or TLR7 activity were detected compared with controls. It is known that TLR2 may bind a number of different ligands, especially lipopeptides related to bacterial cell wall components in addition to endogenously released peptides, ${ }^{29}$ although a yet undiscovered endogenous or exogenous ligand(s) may also activate this receptor. In this study, we showed that the TLR2 homodimer activity (HKLM) was enhanced as distinct from activities of the TLR1/2 (Pam3Csk) or TLR6/2 (FSL1) heterodimers. It is unclear if ligand(s) for TLRs are present in blood from schizophrenia and bipolar patients under basal conditions, which would have the ability to activate these receptors.

Schizophrenia and bipolar disorder are similar in respects to epidemiology, in particular age of onset, incidence in the population and lifetime duration. ${ }^{30}$ In addition, it has become apparent from a number of studies that these disorders share some molecular susceptibility loci. ${ }^{30,31}$ As mentioned before, these disorders both display increases in plasma levels of inflammatory markers. At present, it is not certain why schizophrenia and bipolar patients display greater TLR activity compared with controls or why their pattern is so similar. It has been shown that schizophrenia and bipolar patients appear to be particularly susceptible to stress. ${ }^{32-36}$ It is apparent from both animal models and clinical studies that chronic stress may affect the immune response. ${ }^{37}$ It was reported that repeated social defeat stress enhanced the 
bactericidal activity of splenic macrophages and led to an increase in the expression of TLR2 and TLR4. ${ }^{38}$ The same group also showed that social defeat may activate splenic dendritic cells and enhances TLR activity on these cells as assessed by cytokine output by ligand stimulation. ${ }^{39}$ In addition, chronic restraint stress has been shown to result in immune suppression and this was mediated by TLR4. ${ }^{40,41}$

It has been shown that cytokines themselves can alter TLR expression. ${ }^{42,43}$ Plasma cytokines and acute phase proteins have been shown to be elevated in this cohort of patients and this potentially may explain why there are increases in TLR activity in these patients. Although a number of psychiatric disorders have alterations in the immune system, TLR activity may allow us to differentiate between different disorders, with individual disorders having their own signature TLR increases and decreases. This may lend peripheral TLR activity as a potential biomarker in the diagnosis of psychiatric disorders. The average weight of the schizophrenia cohort was higher than HC. This may be due to antipsychotic drugs, which have been shown to induce weight gain in some patients, ${ }^{44}$ but it does not account for the enhanced immune responses in this study.

We have observed in some instances where there are greater increases in a cytokine following ligand stimulation in one disorder over another. A possible explanation for this may be owing to expression or activity differences between disorders of one of the many downstream signalling molecules that lead to activation of transcription factors following TLR stimulation. Alternatively, it may be for epigenetic reasons, such as decreased transcriptional activity in either disorder for particular cytokines. This would imply that when a ligand activates the receptor and initiates the downstream signalling pathway, there would be less transcriptional activity at the promoter of the given cytokine due to epigenetic silencing/modifications.

Limitations of this study include the lack of drug-free patients. This may have implications for the observed immune changes in schizophrenia and bipolar patients. It is known that antipsychotics may have an effect on plasma cytokine levels. ${ }^{45}$ As a sizeable number of patients were on one or more antipsychotics in the schizophrenia cohort and a mood stabilizer and/or antipsychotics in the bipolar cohort (Table 2), it would be difficult to assess the effect of individual drugs on TLR activity. In addition, bipolar patients were not selected on the basis of the phase of the disorder, and so differences may exist between manic and depressive patients, however, the study is not powered to detect these differences. Similarly, schizophrenia patients were not differentiated on illness severity.

This study has provided novel insights into relationships between TLR activation, plasma cytokine levels and clinical phenotype among a well-characterised group of schizophrenia and bipolar patients. While confirming that certain proinflammatory cytokine levels are increased in plasma among schizophrenia and bipolar patients, we have gone on to describe, what is to our knowledge for the very first time, distinctive patterns of TLR activity in the periphery of psychotic patients. In summary, the observed increase in TLR activity in psychiatric patients implies that following engagement of these receptors by endogenous or exogenous ligands, there would be a greater release of inflammatory cytokines in psychiatric patients. This increase in inflammation may in turn affect neuronal plasticity as has been demonstrated using animal models. ${ }^{5-7}$ This study further suggests a link between inflammation and psychosis.

\section{Conflict of interest}

The authors declare no conflict of interest.

Acknowledgements. The Alimentary Pharmabiotic Centre is a centre for science and technology (CSET) funded by Science Foundation Ireland (SFI), through the Irish Government's National Development Plan. The authors and their work were supported by SFI and GlaxoSmithKline through grant 07/CE/B1368.

1. Freedman R. Schizophrenia. N Engl J Med 2003; 349: 1738-1749.

2. Ross CA, Margolis RL, Reading SA, Pletnikov M, Coyle JT. Neurobiology of schizophrenia. Neuron 2006; 52: 139-153.

3. Sullivan PF. The genetics of schizophrenia. PLOS Med 2005; 2: e212.

4. Brown AS, Derkits EJ. Prenatal infection and schizophrenia: a review of epidemiologic and translational studies. Am J Psychiatry 2010; 167: 261-280.

5. Ellman LM, Deicken RF, Vinogradov S, Kremen WS, Poole JH, Kern DM et al. Structural brain alterations in schizophrenia following fetal exposure to the inflammatory cytokine interleukin-8. Schizophr Res 2010; 121: 46-54.

6. Gilmore JH, Fredrik Jarskog L, Vadlamudi S, Lauder JM. Prenatal infection and risk for schizophrenia: IL-1beta, IL-6, and TNF alpha inhibit cortical neuron dendrite development. Neuropsychopharmacology 2004; 29: 1221-1229.

7. Smith SE, Li J, Garbett K, Mirnics K, Patterson PH. Maternal immune activation alters fetal brain development through interleukin-6. J Neurosci 2007; 27: 10695-10702.

8. Maes M, Delange J, Ranjan R, Meltzer HY, Desnyder R, Cooremans W et al. Acute phase proteins in schizophrenia, mania and major depression: modulation by psychotropic drugs. Psychiatry Res 1997; 66: 1-11.

9. Potvin S, Stip E, Sepehry AA, Gendron A, Bah R, Kouassi E. Inflammatory cytokine alterations in schizophrenia: a systematic quantitative review. Biol Psychiatry 2008; 63: 801-808.

10. Belmaker RH. Bipolar disorder. N Engl J Med 2004; 351: 476-486.

11. Merikangas KR, Akiskal HS, Angst J, Greenberg PE, Hirschfeld RM, Petukhova M et al. Lifetime and 12-month prevalence of bipolar spectrum disorder in the National Comorbidity Survey replication. Arch Gen Psychiatry 2007; 64: 543-552.

12. Kim YK, Jung HG, Myint AM, Kim H, Park SH. Imbalance between pro-inflammatory and anti-inflammatory cytokines in bipolar disorder. J Affect Disord 2007; 104: 91-95.

13. O'Brien SM, Scully P, Scott LV, Dinan TG. Cytokine profiles in bipolar affective disorder: focus on acutely ill patients. J Affect Disord 2006; 90: 263-267.

14. Ortiz-Dominguez A, Hernandez ME, Berlanga C, Gutierrez-Mora D, Moreno J, Heinze G et al. Immune variations in bipolar disorder: phasic differences. Bipolar Disord 2007; 9: 596-602.

15. Brietzke E, Stertz L, Fernandes BS, Kauer-Sant'anna M, Mascarenhas M, Escosteguy Vargas $A$ et al. Comparison of cytokine levels in depressed, manic and euthymic patients with bipolar disorder. J Affect Disord 2009; 116: 214-217.

16. Brietzke E, Kauer-Sant'Anna M, Teixeira AL, Kapczinski F. Abnormalities in serum chemokine levels in euthymic patients with bipolar disorder. Brain Behav Immun 2009; 23: 1079-1082.

17. Takeuchi O, Akira S. Pattern recognition receptors and inflammation. Cell 2010; 140: 805-820.

18. Nishimura $M$, Naito $S$. Tissue-specific mRNA expression profiles of human toll-like receptors and related genes. Biol Pharm Bull 2005; 28: 886-892.

19. Leucht S, Kane JM, Kissling W, Hamann J, Etschel E, Engel RR. What does the PANSS mean? Schizophr Res 2005; 79: 231-238.

20. Opler MG, Yang LH, Caleo S, Alberti P. Statistical validation of the criteria for symptom remission in schizophrenia: preliminary findings. BMC Psychiatry 2007; 7: 35.

21. Addington D, Addington J, Maticka-Tyndale E. Assessing depression in schizophrenia: the Calgary Depression Scale. Br J Psychiatry Suppl 1993; 22: 39-44.

22. Berk M, Ng F, Wang WV, Calabrese JR, Mitchell PB, Malhi GS et al. The empirical redefinition of the psychometric criteria for remission in bipolar disorder. $J$ Affect Disord 2008; 106: 153-158.

23. Hamilton M. A rating scale for depression. J Neurol Neurosurg Psychiatry 1960; 23: 56-62.

24. Masand PS, Eudicone J, Pikalov A, McQuade RD, Marcus RN, Vester-Blokland E et al. Criteria for defining symptomatic and sustained remission in bipolar I disorder: a post-hoc analysis of a 26-week aripiprazole study (Study CN138-010). Psychopharmacol Bull 2008; 41: 12-23.

25. John CD, Buckingham JC. Cytokines: regulation of the hypothalamo-pituitaryadrenocortical axis. Curr Opin Pharmacol 2003; 3: 78-84. 
26. Chrousos GP. The hypothalamic-pituitary-adrenal axis and immune-mediated inflammation. N Engl J Med 1995; 332: 1351-1362.

27. Dantzer R, O'Connor JC, Freund GG, Johnson RW, Kelley KW. From inflammation to sickness and depression: when the immune system subjugates the brain. Nat Rev Neurosci 2008; 9: 46-56.

28. Brown AS, Hooton J, Schaefer CA, Zhang $H$, Petkova $E$, Babulas $V$ et al. Elevated maternal interleukin-8 levels and risk of schizophrenia in adult offspring. Am J Psychiatry 2004; 161: 889-895.

29. Takeuchi O, Akira S. Pattern recognition receptors and inflammation. Cell 2010; 140 805-820.

30. Berrettini WH. Are schizophrenic and bipolar disorders related? A review of family and molecular studies. Biol Psychiatry 2000; 48: 531-538.

31. Mitchell KJ. The genetics of neurodevelopmental disease. Curr Opin Neurobiol 2010; 21: 197-203.

32. Corcoran C, Walker E, Huot R, Mittal V, Tessner K, Kestler $L$ et al. The stress cascade and schizophrenia: etiology and onset. Schizophr Bull 2003; 29: 671-692.

33. Walker E, Mittal V, Tessner K. Stress and the hypothalamic pituitary adrenal axis in the developmental course of schizophrenia. Annu Rev Clin Psychol 2008; 4 : 189-216.

34. Gispen-de Wied CC. Stress in schizophrenia: an integrative view. Eur J Pharmacol 2000; 405: 375-384.

35. Johnson SL, Roberts JE. Life events and bipolar disorder: implications from biological theories. Psychol Bull 1995; 117: 434-449.

36. Post RM, Leverich GS, Xing G, Weiss RB. Developmental vulnerabilities to the onset and course of bipolar disorder. Dev Psychopathol 2001; 13: 581-598.

37. Glaser R, Kiecolt-Glaser JK. Stress-induced immune dysfunction: implications for health Nat Rev Immunol 2005; 5: 243-251.

38. Bailey MT, Engler H, Powell ND, Padgett DA, Sheridan JF. Repeated socia defeat increases the bactericidal activity of splenic macrophages through a
Toll-like receptor-dependent pathway. Am J Physiol Regul Integr Comp Physiol 2007; 293: R1180-R1190.

39. Powell ND, Bailey MT, Mays JW, Stiner-Jones LM, Hanke ML, Padgett DA et al. Repeated social defeat activates dendritic cells and enhances toll-like receptor dependent cytokine secretion. Brain Behav Immun 2009; 23: 225-231.

40. Zhang Y, Woodruff M, Zhang Y, Miao J, Hanley G, Stuart C et al. Toll-like receptor 4 mediates chronic restraint stress-induced immune suppression. J Neuroimmunol 2008; 194: 115-122.

41. Zhang $Y$, Zhang $Y$, Miao J, Hanley G, Stuart C, Sun $X$ et al. Chronic restraint stress promotes immune suppression through toll-like receptor 4-mediated phosphoinositide 3-kinase signaling. J Neuroimmunol 2008; 204: 13-19.

42. Hermoso MA, Matsuguchi T, Smoak K, Cidlowski JA. Glucocorticoids and tumor necrosis factor alpha cooperatively regulate toll-like receptor 2 gene expression. Molecular and Cellular Biology 2004; 24: 4743-4756.

43. Sakai A, Han J, Cato AC, Akira S, Li JD. Glucocorticoids synergize with IL-1beta to induce TLR2 expression via MAP kinase phosphatase-1-dependent dual inhibition of MAPK JNK and p38 in epithelial cells. BMC Mol Biol 2004; 5: 2

44. Newcomer JW. Second-generation (atypical) antipsychotics and metabolic effects: a comprehensive literature review. CNS Drugs 2005; 19(Suppl 1): 1-93.

45. Drzyzga L, Obuchowicz E, Marcinowska A, Herman ZS. Cytokines in schizophrenia and the effects of antipsychotic drugs. Brain Behav Immun 2006; 20: 532-545.

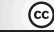

Translational Psychiatry is an open-access journal published by Nature Publishing Group. This work is licensed under the Creative Commons Attribution-NoncommercialNo Derivative Works 3.0 Unported License. To view a copy of this license, visit http://creativecommons.org/licenses/by-nc-nd/3.0/ 